\title{
Tobacco rattle virus (TRV)-Mediated Silencing of Nicotiana benthamiana ARGONAUTES (NbAGOs) Reveals New Antiviral Candidates and Dominant Effects of TRV-NbAGO1
}

\author{
Denis Odokonyero, Maria R. Mendoza, Peter Moffett, and Herman B. Scholthof
}

First, second, and fourth authors: Department of Plant Pathology and Microbiology, Texas A\&M University, College Station; and third author: Département de Biologie, Université de Sherbrooke, Sherbrooke, Quebec, Canada.

Current address of D. Odokonyero: Department of Biophysics and Biochemistry, Texas A\&M University, College Station 77843. Accepted for publication 11 April 2017.

\begin{abstract}
The objective of this study was to determine the contribution of different ARGONAUTE proteins in Nicotiana benthamiana (NbAGOs) to the defense against silencing sensitive GFP-expressing viral constructs based on Tomato bushy stunt virus (TBSV) (Tombusvirus), Sunn-hemp mosaic virus (Tobamovirus), and Foxtail mosaic virus (Potexvirus). Upon Tobacco rattle virus (TRV)-mediated down-regulation of $\mathrm{NbAGO1,4,}$ 5 , or 6 , no effects were noted on susceptibility to any virus construct, whereas knockdown of $\mathrm{NbAGO2}$ specifically prevented silencing of P19defective TBSV (TGdP19). Down-regulation of a new gene referred to as NbAGO5L showed some reduced silencing for TGdP19 but not for the other two virus constructs, whereas silencing of $\mathrm{NbAGO7}$ gave rise to a subtle

increase in susceptibility to all three viruses. Co-infiltrating different TRV$N b A G O$ constructs simultaneously did not enhance virus susceptibility. However, an unexpected finding was that whenever the TRV-NbAGO1 construct was present, this compromised silencing of genes targeted by co-infiltrated constructs, as shown upon co-infiltration of TRV-NbAGOI with either TRV-NbAGO2 or TRV-Sul (targeting Magnesium chelatase I). Only after a prolonged period (approximately 2 months) did TRV-Sulmediated systemic bleaching occur in these co-infected plants, suggesting that TRV-NbAGO1 hinders the silencing ability of other TRV-NbAGO constructs. In conclusion, this study revealed new antiviral $N b A G O s$ and dominant effects of silencing $N b A G O 1$.
\end{abstract}

RNA silencing is a posttranscriptional regulatory process for which key roles are attributed to ARGONAUTE proteins (AGOs), a highly conserved, ubiquitously expressed protein family present in almost all eukaryotes, bacteria, and archaea (Hock and Meister 2008; Hutvagner and Simard 2008). They are extremely diverse in number and function between different species. For example, Caenorhabditis elegans encodes as many as 27 AGOs (Kim et al. 2005), while Schizosaccharomyces pombe encodes only one AGO that is involved in both transcriptional and posttranscriptional silencing (Sigova et al. 2004). The Drosophila melanogaster genome encodes five AGO protein family members: Aubergine (Aub), Piwi, DmAGO1, DmAGO2, and DmAGO3 (Carmell et al. 2002; Kataoka et al. 2001; Williams and Rubin 2002), each of which is thought to play a distinct role in RNA silencing. For example, while DmAGO1 is required for miRNA function, DmAGO2 is a crucial component of the RNA-induced silencing complex in siRNA-triggered RNA interference.

In plants, Arabidopsis encodes 10 characterized AGOs (Bohmert et al. 1998; Fang and Qi 2016; Hutvagner and Simard 2008; Manavella et al. 2011; Morel et al. 2002; Vaucheret 2008; Zhang et al. 2011); Musa acuminata subsp. malaccensis (a wild relative of the commercialized banana) encodes an estimated $15 A G O$ genes or loci containing PIWI domain sequences (Teo et al. 2011); rice (Oryza sativa) encodes 18 genes in the AGO family (Fujita et al. 2010; Itoh et al. 2005; Nonomura et al. 2007; Raghavan 1988; Wu et al. 2009b) while $15 A G O$ genes were identified in the tomato (Solanacearum lycopersicum) genome (Bai et al. 2012), 17 in maize

Corresponding author: H. B. Scholthof; E-mail address: herscho@tamu.edu

*The $\boldsymbol{e}$-Xtra logo stands for "electronic extra" and indicates that six supplementary figures are published online.

(c) 2017 The American Phytopathological Society
(Zea mays) (Qian et al. 2011; Tameling and Baulcombe 2007; Zhai et al. 2014), and 15 in poplar (Populus trichocarpa) (Zhao et al. 2015).

The high variability in the number of identified AGOs compared with the roles generally played by AGO proteins leads to the speculation that there may exist organism-specific overlapping, redundant or additive roles among AGOs. It is very likely therefore, that when a single member of the $A G O$ family is silenced, only a small effect, like a delayed or nonpersistent phenotype will be observed, since another member takes over the role previously carried out by the silenced $A G O$. This speculation is not far-fetched, in fact, in Arabidopsis it was observed that Plantacyanins of the phytocyanin family of blue copper proteins (cupredoxins) (Dong et al. 2005) are regulated through either AGO1 or AGO2 via miR408. Neither single mutations of agol nor ago2 individually impeded the regulation of Plantacyanin, rather only an agol/ago2 double mutant appears compromised in miR408-mediated regulation of Plantacyanin, suggesting that AtAGO1 and AtAGO2 have redundant roles in this regulation (Maunoury and Vaucheret 2011).

Both Arabidopsis AGO4 and 6 direct RNA silencing pathway at the transcriptional level through heterochromatin silencing (Havecker et al. 2010; Zheng et al. 2007). Zheng et al. (2007) showed that when the expression of a transcriptionally silent transgene was reactivated in the ros 1 mutant background, the level of transcriptional reactivation was higher in the ago4/ros 1 double mutant background than in the ago6/ros 1 mutant. This suggests that although AGO6 plays a role in sRNA-directed heterochromatin RNA silencing, it is not as widespread as that directed by AGO4 in Arabidopsis. The level of transgene reactivation was demonstrated to be even higher in the ago4/ago6/ros 1 triple mutant compared with either of the analyzed double mutants, clearly showing overlapping functions. Furthermore, array and reporter gene expression data reveal that the expression pattern of AGO6 overlaps with that of AGO4 (Schmid et al. 2005). Taken together, these 
observations suggest that these two Arabidopsis AGO family members act on a shared subset of repeat elements, and that their overlapping function occurs in analogous tissues and at the similar developmental time points (Kim et al. 2011).

Members of the AGO protein family are also known to regulate the expression and function of each other. In Arabidopsis, AGO10 regulates shoot apical meristems (SAM) by specifically interacting with miR166/165. AtAGO1 is also capable of binding to miR166; however, AtAGO10 has a higher binding affinity for miR166 than does AtAGO1. It therefore acts as a decoy for miR166/165 to be able to maintain the SAM in the required tissues preventing their incorporation into AGO1 complexes and subsequent repression of the class III homeodomain-leucine zipper transcription factors, targets of the mi166/165 (Zhu et al. 2011).

In Arabidopsis, AGO1 has been implicated as a key factor in the induction of antiviral defenses (Baumberger et al. 2007; Bortolamiol et al. 2007, 2008; Carbonell and Carrington 2015; Csorba et al. 2007; Dzianott et al. 2012; Garcia-Ruiz et al. 2015; Havelda et al. 2008; Morel et al. 2002; Qu et al. 2008; Wang et al. 2011b; Zhang et al. 2006). At the same time, AtAGO2 (Carbonell et al. 2012; Garcia-Ruiz et al. 2015; Harvey et al. 2011; Jaubert et al. 2011; Ma et al. 2015; Wang et al. 2011b; Zhang et al. 2012), AtAGO3 (Alazem et al. 2017), AtAGO4 (Bhattacharjee et al. 2009; Brosseau et al. 2016; Hamera et al. 2012; Ma et al. 2015), AtAGO5 (Brosseau and Moffett 2015; Garcia-Ruiz et al. 2015), AtAGO7 (Carbonell et al. 2012; Garcia-Ruiz et al. 2015; Qu et al. 2008), and AtAGO10 (Garcia-Ruiz et al. 2015) have also been identified as participating in antiviral silencing. Another layer of complexity was observed regarding function and tissue specificity of AGOs in Arabidopsis suggesting that AGOs may not strictly play distinct antiviral defense roles but cooperatively coordinate response in a spatiotemporal manner (Brosseau and Moffett 2015; GarciaRuiz et al. 2015).

Redundancy and cooperativeness in plant antiviral defense mechanisms have also been reported, whereupon a breakdown of the first defense mechanism by viral suppressors that target AGO1 leads to the up-regulation of AGO2, which is normally suppressed by AGO1 via miR403 (Allen et al. 2005; Harvey et al. 2011; Wang et al. 2011b). Similarly in rice, the antiviral function of AGO18 depends on its capacity to sequester miR 168 and thereby alleviate repression of rice AGO1, which is essential for antiviral RNAi (Wu et al. 2015). All these aforementioned studies allude to an interplay and crosstalk between AGOs during various developmental and antiviral roles.

$N$. benthamiana has served as a model for studying plant-virus interactions due to its susceptibility to a wide range of viruses (Clemente 2006; Goodin et al. 2008), for examining protein function and intracellular localization (Clemente 2006; Sparkes et al. 2006; Wydro et al. 2006), as well as for functional confirmation of genetic discoveries made in Arabidopsis (Zhou and Ni 2010). Compared with other models, less is known about the silencing components of $N$. benthamiana although transcriptome analyses verify their expression (Nakasugi et al. 2013). Apart from being a critical component of plant development (Jones et al. 2006), $N$. benthamiana AGO1 (NbAGO1) is vital to antiviral defense against Tomato ringspot virus (ToRSV) in a temperature dependent manner (Ghoshal and Sanfacon 2014). NbAGO2 protects against a suppressor-defective Tomato bushy stunt virus (TBSV) (Scholthof et al. 2011) and has recently been implicated in some level of resistance to Tobacco mosaic virus and Potato virus $X$ (PVX) (Odokonyero et al. 2015).

Considering the variety of AGOs, their interactions, and their possible roles in virus defense, discussed above, our aim in the present study was to examine the antiviral contributions of several NbAGOs in N. benthamiana and address the hypothesis that some may have overlapping, redundant or additive roles. For this purpose, we used Tobacco rattle virus (TRV)-mediated down-regulation of individual, as well as various combinations of, $N b A G O s$, to test the effect on susceptibility to silencing-sensitive GFP-expressing virus constructs based on TBSV (Tombusvirus) (Qiu et al. 2002), Sunnhemp mosaic virus (SHMV) (Tobamovirus) (Liu and Kearney 2010b), and Foxtail mosaic virus (FoMV) (Potexvirus) (Liu and Kearney 2010a). The results reveal novel antiviral roles for $N b A G O 7$ and an uncharacterized gene (NbAGO5L). During attempts to silence combinations of $N b A G O s$, a dominant effect was noted whenever treatments involved the use of TRV-NbAGOl, which manifested itself by interference with the performance of other co-infiltrated TRV-NbAGOs.

\section{MATERIALS AND METHODS}

AGO sequence identification, agroinfiltration of silencing constructs, GFP-chimeric constructs, and UV analyses. TRV constructs of $N$. benthamiana $A G O 1$ and $A G O 4$ were acquired from colleagues (Jones et al. 2006). Based on their similarity to the, at that time, 10 known $A G O$ genes in Arabidopsis, NbAGOs 5, 6, and 7 fragments were identified for $N$. benthamiana (Supplementary Figs. $\mathrm{S} 1$ and S2) which were then synthetically synthesized (GenScript, Piscataway, NJ), whereas $N b A G O 2$ and $N b A G O 5 L$ were obtained by RT-PCR of mRNA as described previously (Scholthof et al. 2011), using primers based on deposited $N$. benthamiana sequences available at that time. The sources for the Arabidopsis sequences are provided with Supplementary Figure S2. The $N b A G O$ fragments of interest were cloned into the multiple cloning site of the TRV genomic RNA2 construct pTV:00 (Ratcliff et al. 2001), for matters of consistency referred to in this study as TRV-00, with the position of the fragments with respect to encoded conserved AGO domains indicated in Supplementary Figure S3.

Both TRV-NbAGO and TRV genomic RNA1 constructs were electroporated into the GV3101 (also known as pMP90RK) strain of Agrobacterium tumefaciens. Agrobacterium cultures were grown overnight (16 to $20 \mathrm{~h}$ ) under constant shaking ( $200 \mathrm{rpm}$ ) at $28^{\circ} \mathrm{C}$ in $5 \mathrm{ml}$ of Luria broth media with kanamycin at $50 \mathrm{mg} / \mathrm{liter}$. Agrobacterium cells were collected by centrifugation at 3,500 rpm for $20 \mathrm{~min}$ and the cells resuspended in infiltration media $(10 \mathrm{mM}$ $\mathrm{MgCl}_{2}$ ) to a final optical density at $600 \mathrm{~nm}$ of 0.5 . Five-week-old plant leaves were agroinfiltrated on the abaxial side with both TRV constructs. Each construct was individually infiltrated so that each leaf at least received all TRV-NbAGO constructs in a given combination. Two to four leaves per plant were infiltrated as necessary and grown at $25^{\circ} \mathrm{C} / 22^{\circ} \mathrm{C}$ day/night temperature cycles and 16-h light/8-h dark cycles for a period of 3 to 5 weeks during which TRV-NbAGO viral constructs replicated and accumulated within the plant as silencing of its endogenous genes occurred.

All possible combinations of (TRV-induced silencing constructs) TRV-NbAGO1, 2, 4, 5, 5L, 6 , and 7 were manually computed by rearranging all constructs into combinations ranging from those that include all seven constructs to single constructs. The resulting total of $126 \mathrm{TRV}-\mathrm{NbAGO}$ construct combinations was set up in triplicate and TRV constructs agroinfiltrated to initiate silencing of the $N b A G O$ genes.

TBSV, with (TG) and without its P19 silencing suppressor (TGdP19), FoMV-GFP (Liu and Kearney 2010b), and SHMV-GFP (Liu and Kearney 2010b) chimeric constructs (Supplementary Fig. S4) were also transformed into Agrobacterium strain GV3101. Cultures were prepared and infiltrated in half-leaf assays whereby each half of the leaf was infiltrated with and without a P19 silencing suppressor. Accumulation of GFP signal was monitored using a hand-held $365 \mathrm{~nm}$ UV lamp in the dark.

RNA extraction, cDNA synthesis, and semiquantitative PCR to determine systemic movement of viral constructs. Total RNA was extracted from systemic/newly formed leaves by thoroughly macerating $0.1 \mathrm{~g}$ of plant tissue in $750 \mu \mathrm{l}$ of extraction buffer (78.56 mM Tris, $\mathrm{pH} 8.2,39.28 \mathrm{mM} \mathrm{LiCl}, 1.96 \mathrm{mM}$ EDTA, $0.44 \%$ SDS, $78.57 \mathrm{NaAc}, \mathrm{pH} 4$, phenol, chloroform, and $\beta$-mercaptoethanol) and centrifuged at $12,000 \mathrm{rpm}$ for $6 \mathrm{~min}$ at room temperature. The 
resulting supernatant was collected and mixed in a 1:1 ratio with a phenol/chloroform/isoamyl-alcohol (25:24:1) mixture and further centrifuged for $6 \mathrm{~min}$. The supernatant was mixed with chloroform at 1:1 volume ratio and centrifuged at 12,000 rpm for $6 \mathrm{~min}$. The supernatant was immediately collected, mixed with $1 / 3$ volume of $8 \mathrm{M} \mathrm{LiCl}$, and incubated overnight at $-20^{\circ} \mathrm{C}$ for precipitation. It was then centrifuged at $13,000 \mathrm{rpm}$ for $20 \mathrm{~min}$ at $4^{\circ} \mathrm{C}$, the pellet washed in $70 \%$ ethanol, air-dried, and resuspended in $30 \mu$ of DEPC water.

cDNA was synthesized using M-MLV reverse transcription (Life Technologies, CA) according to the manufacturer's protocol. Since TRV does not possess a poly-A tail, first-strand cDNA synthesis to monitor TRV construct movement was carried out using the reverse primer for the TRV multiple cloning site, while oligo(dT) was used for cDNA synthesis to verify silencing of expression levels of $\mathrm{NbAGO}$ mRNAs. RT-PCR to monitor systemic movement of the constructs was carried out by using TRV multiple cloning site (MCS) primers (TRV MCS forward primer: 5'-GAGTGGAGGTCCGATACGTC-3' and TRV MCS reverse primer: 5'-CAGTGAGCGCGCGTAATA-3') while $N b A G O$ gene-specific primers amplifying regions outside sequences inserted in the TRV vector were used to evaluate expression levels of the silenced genes (see below).

Verification of specific $N b A G O$ silencing via quantitative real-time PCR. Primers were designed using Primerquest online program (IDT, 2012) based on Bio-Rad real-time PCR and MIQE (minimum information for publication of quantitative real-time PCR experiments) (Bustin 2002, 2010; Bustin et al. 2009; Taylor et al. 2010) guidelines to amplify regions of the endogenous $N b A G O$ genes that were not part of fragment inserted into the TRV vector to accurately represent silencing of the plant $N b A G O$ transcripts. Furthermore, to avoid amplification of regions of other $N b A G O$ genes, all currently known sequences of $N b A G O 1,2,4,5,6$, 7 , and $5 L$ were aligned using MUSCLE (MUltiple Sequence Comparison by Log-Expectation) online software (Edgar 2004).
The output files were customized for easy viewing using BOXSHADE 3.21 online software (http://ch.embnet.org/, 2012) and only unique sequence regions were selected for primer design (Supplementary Fig. S5).

A comparative method ( $\Delta \mathrm{Ct})$ (Pfaffl and Hageleit 2001) that analyzes the differences in $\mathrm{Ct}$ values between the target $(\mathrm{NbAGO})$ and reference actin gene (Bezier et al. 2002; Langer et al. 2002; Thomas et al. 2003), which is abundantly and universally expressed in $N$. benthamiana cells, were first calculated to normalize initial template concentrations. After normalization, the $\mathrm{Ct}$ values were then converted to a linear scale by calculating the $\Delta \mathrm{Ct}$ values. The resulting values were portrayed on $2 \mathrm{D}$ column charts with error bars to validate significance of the biological and technical repeats.

\section{RESULTS}

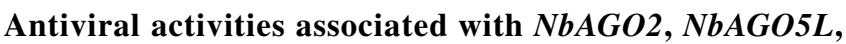
and $N \boldsymbol{B A G O 7 . ~ T h r e e ~ t o ~ f o u r ~ w e e k s ~ a f t e r ~ a g r o i n f i l t r a t i o n ~ o f ~}$ $N$. benthamiana with individual TRV constructs, RT-PCR results validated the systemic movement and accumulation of each TRV$N b A G O$ in separate plants (Fig. 1A). As opposed to silencing with TRV-NbAGO1, 2, and $5 L$ (discussed below), preliminary tests showed that infections with TRV-NbAGO4, 5, 6, and 7 were not associated with any noticeable phenotype. Nevertheless, evidence to verify that the level of target mRNA for these $N b A G O s$ had indeed been down-regulated was provided upon real-time RT-PCR (Fig. $1 \mathrm{~B})$. When considering the different $y$ axis scales in Figure $1 \mathrm{~B}$, it is evident that $\mathrm{NbAGO4}$ expression (in 00-control plants) is substantially higher compared with the other NbAGOs investigated. The establishment of silencing for other $N b A G O$ targets was routinely confirmed by observing typical known phenotypes associated with silencing. For instance, Magnesium chelatase $(\mathrm{MgChl})$ silencing by
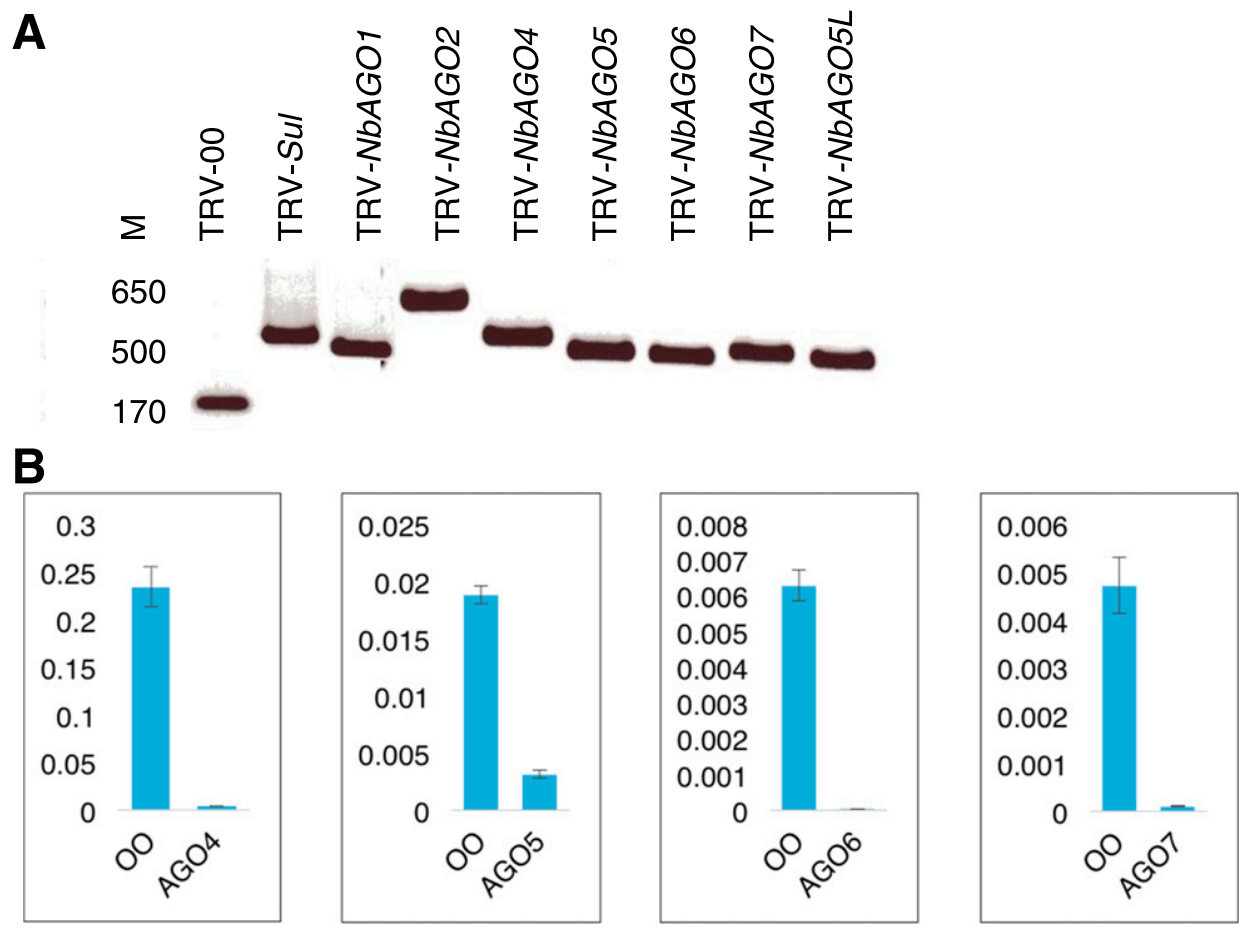

Fig. 1. Accumulation of Tobacco rattle virus (TRV)-NbAGOs and effects on expression of the plant analogs. A, RT-PCR using TRV multiple cloning site primers showing infectivity, integrity, and ability for systemic spread of the TRV constructs to indicate presence of intact inserts of $N b A G O s$ as indicated. TRV-00 is empty vector and TRV-Sul silences Magnesium chelatase I. Numbers on the left indicate sizes in base pairs. B, qRT-PCR analysis of individual NbAGO4, 5, 6, and 7 (AGO4-7) transcript levels in silenced plants. The relative $N b A G O$ transcript expression levels (deduced from observed SYBR green arbitrary fluorescence units and normalized to an internal control gene) based on qRT-PCR with indicated primers are plotted on the $y$ axes (with different scales for individual NbAGOs) and the sampled plants (OO for control plants infiltrated with an empty TRV virus vector and the specific $N b A G O$-silenced plants) on the $x$ axes. Comparative ( $\triangle \mathrm{Ct}$ ) internal normalization was performed using actin as a reference gene. 
TRV-Sul was evident by leaf photobleaching and down-regulation of $\mathrm{NbAGO1}$ resulted in leaf and floral deformations (see below for both). As another example, silencing of $\mathrm{NbAGO2}$ allowed accumulation of GFP (Fig. 2) from a suppressor-defective TBSV-GFP chimeric construct (TGdP19), that is otherwise subject to NbAGO2-mediated silencing (Odokonyero et al. 2015; Scholthof et al. 2011).

The present study also included an unknown $N b A G O$, initially referred to as $N b A G O X$, but closer scrutiny with updated information in databases revealed similarity with AtAGO5 and NbAGO5 (Supplementary Fig. S6); and henceforth referred to as NbAGO5-Like (NbAGO5L). Considering this, and based on the results obtained for $N b A G O 5$ (Fig. 2), it was surprising to find that upon VIGS of $N b A G O 5 L$, a relatively low but reproducible level of GFP fluorescence was visible upon agroinfiltration with TGdP19 (Fig. 2). The GFP intensity levels were notably lower than those observed with TdGP19 on NbAGO2 silenced plants, but was visible and persistent (Fig. 2). In contrast, when silencing-sensitive GFP-expressing SHMV and FoMV constructs were agroinfiltrated onto the $N b A G O 5 L$ or $N b A G O 2$ silenced plants, no accumulation of GFP was observed unless the construct was supplemented with a P19 silencing suppressor (Fig. 3) suggesting that silencing of $\mathrm{NbAGO5L}$ and $\mathrm{NbAGO} 2$ is not sufficient to rescue these suppressordefective viruses.

NbAGO7 silenced plants also consistently showed an early but short-lived accumulation of GFP upon infection, not only with the TBSV (TGdP19), but also with SHMV- and FoMV-based constructs (Fig. 4). This early GFP accumulation was not witnessed in nonVIGSed plants (Fig. 4) or in plants infiltrated with TRV-00 also referred to as TV:00 (Ratcliff et al. 2001), or other TRV-NbAGOs (Figs. 2 and 3) (not shown). These results indicate that the early GFP accumulation is related to a general antiviral defense activity of

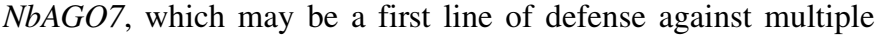
viruses.

Irrespective of the GFP-expressing virus used, individually si-

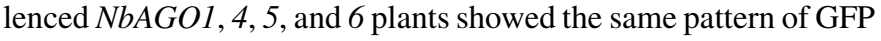
accumulation as noninfiltrated and empty TRV vector infiltrated plants, typified by the property that GFP accumulation was only detected when the P19 silencing suppressor was expressed (Fig. 2) (data not shown).

Dominant effects upon agroinfiltration of $N$. benthamiana with TRV-NbAGO1. As outlined in the introduction, it appears that several $\mathrm{NbAGOS}$ may function at different levels in antiviral silencing. We thus asked whether it would be possible to observe additive or previously masked effects of different NbAGOs. Therefore, the aim was to simultaneously silence more than one $N b A G O$ upon co-infection of plants with different TRV-NbAGO constructs. Substantial effort was devoted to this aspect but the results we obtained were often inconsistent and difficult to interpret, although at least one commonality surfaced, as described below.

Whenever $N$. benthamiana plants were agroinfiltrated with different combinations of TRV-NbAGOs, the pleiotropic developmental phenotypes associated with $\mathrm{NbAGO1}$ silencing (Fig. 5A) were consistently prominent in all silencing combinations that included the TRV-NbAGO1 construct (not shown). Curiously however, we also reproducibly observed that whenever the TRV$\mathrm{NbAGO} 2$ was included in a silencing combination that also included the TRV-NbAGO1 construct, no GFP accumulated in the leaves following agroinfiltration of TGdP19, suggesting that NbAGO2 had not been effectively silenced (Fig. 5B).

The above observations implied that in the presence of TRVNbAGO1, the performance of other TRV constructs in the plant had been suppressed or outcompeted. In order to visually document this phenomenon more prominently, two TRV constructs that each cause a clearly discernible phenotype were selected for coinfiltration: (i) TRV-NbAGO1 causing leaf and floral deformations (Fig. 5A) and (ii) TRV-Sul; also known as TV:Sul (Ratcliff et al. 2001) (Fig. 6); causing loss of the green chlorophyll pigment starting from the newly emerging leaves but gradually spreading to the older leaves (Papenbrock et al. 2000). To examine this, one set of plants was infiltrated with TRV-NbAGOl alone, another with both TRV-NbAGO1 and TRV-Sul, and a final set with only TRV-Sul.

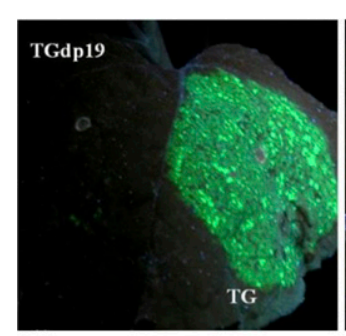

EV

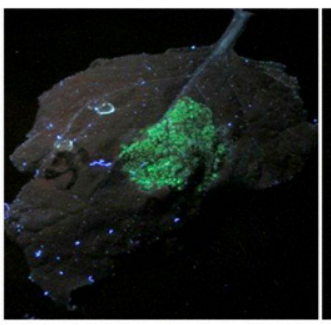

NbAGO1

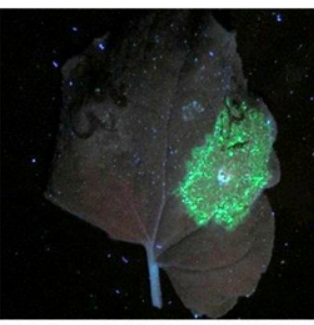

NbAGO4

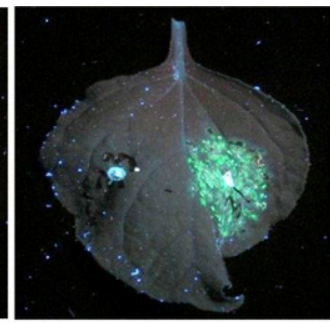

NbAGO5

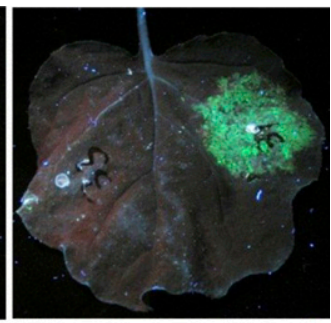

NbAG06

silenced

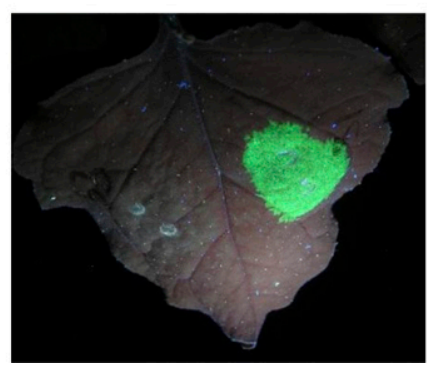

WT

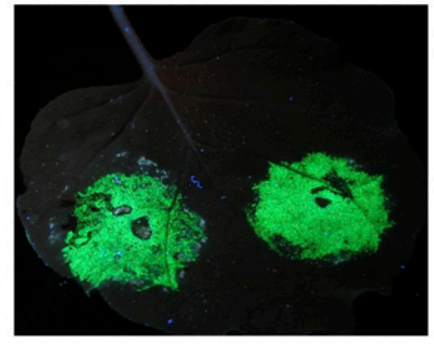

NbAGO2

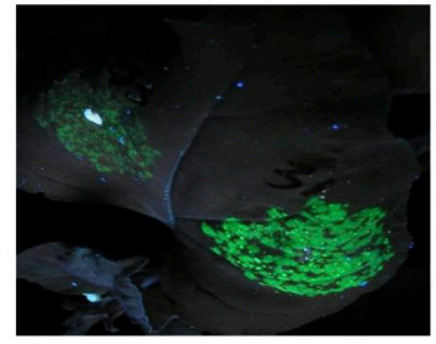

NbAGO5L

\section{silenced}

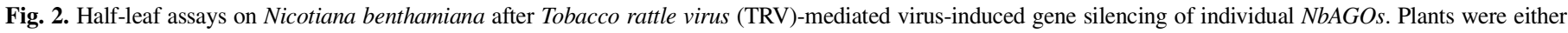

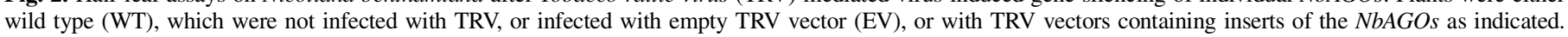

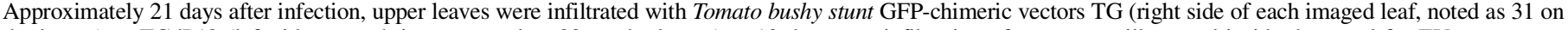
the leaves) or TGdP19 (left side on each image, noted as 33 on the leaves) at 10 days post-infiltration of vectors, as illustrated inside the panel for EV. 
Approximately 5 days after initiation of silencing, newly formed systemic leaves on the plants only infiltrated with the TRV-Sul started showing the leaf-photobleaching phenotype characteristic of silencing of $\mathrm{MgChl}$, and by 10 days, the loss of pigment had spread to the lower leaves (Fig. 6A). Interestingly however, the plants co-infiltrated with both TRV-NbAGOI and TRV-Sul constructs showed no photobleaching phenotype during the same time (Fig. 6A). It was also observed that developmental effects associated with
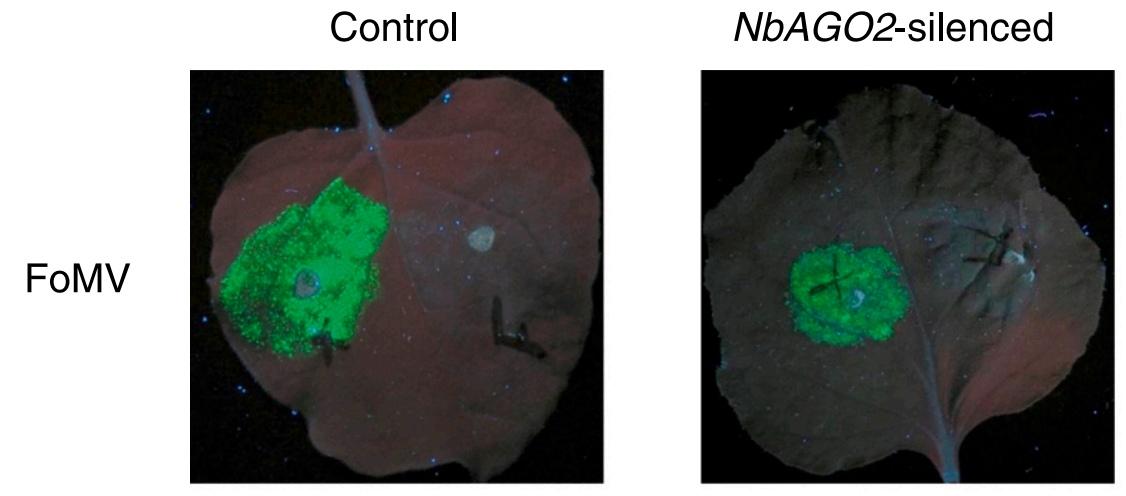

NbAGO5L-silenced

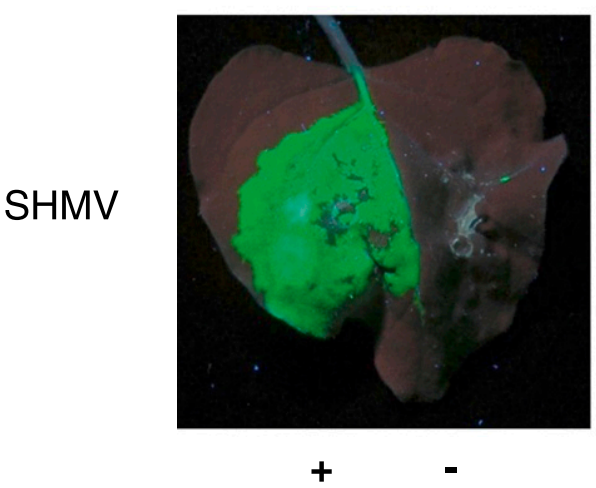

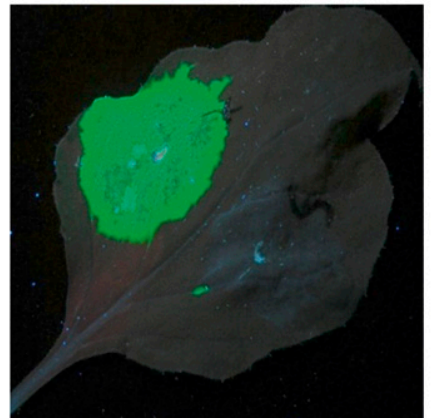

$+$
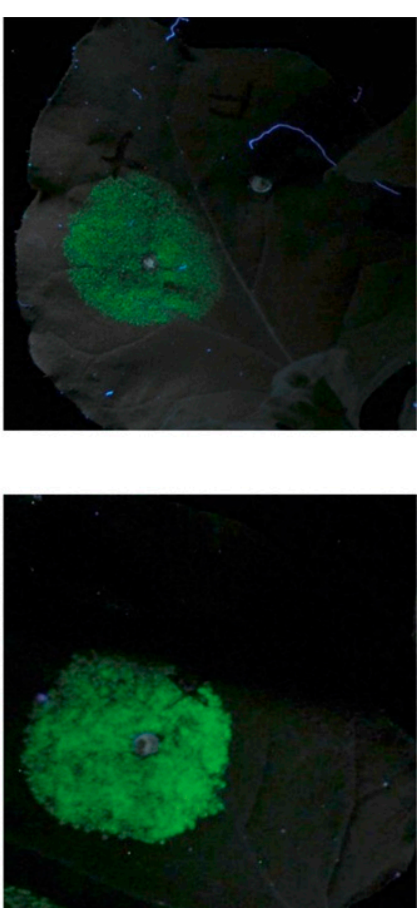

$+$

Fig. 3. Half-leaf assays on uninfected control, $N b A G O 2$-silenced or $N b A G O 5 L$-silenced Nicotiana benthamiana using Foxtail mosaic virus (FoMV) and Sunn-hemp mosaic virus (SHMV) GFP-expressing constructs. Gene silencing was initiated in 4-week-old plants with Tobacco rattle virus (TRV) containing inserts of

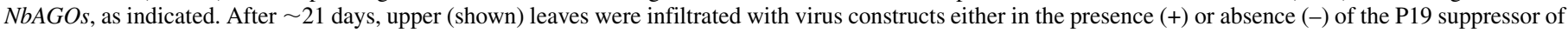
silencing.

A

control

2 days

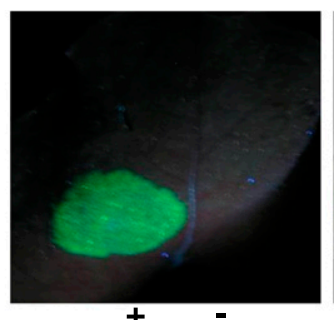

10 days

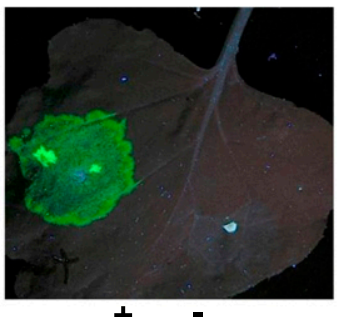

$+\quad-$

NbAGO7-silenced
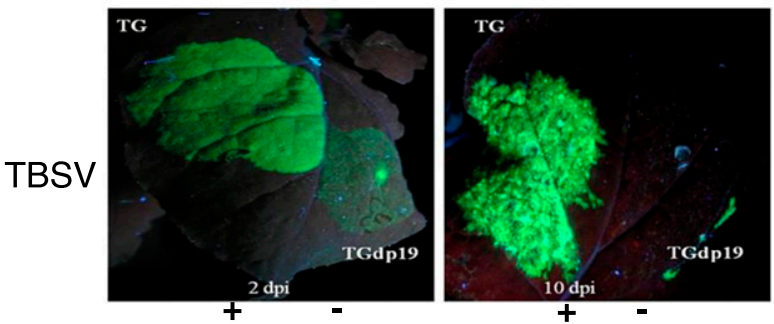

B

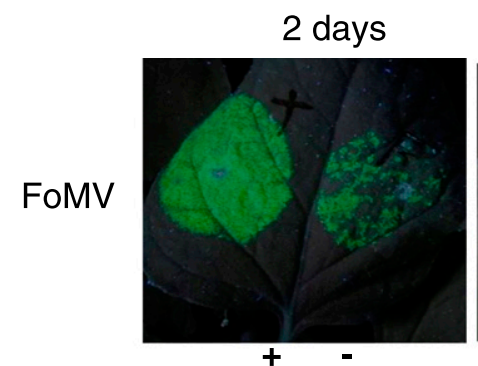

\section{NbAGO7-silenced}
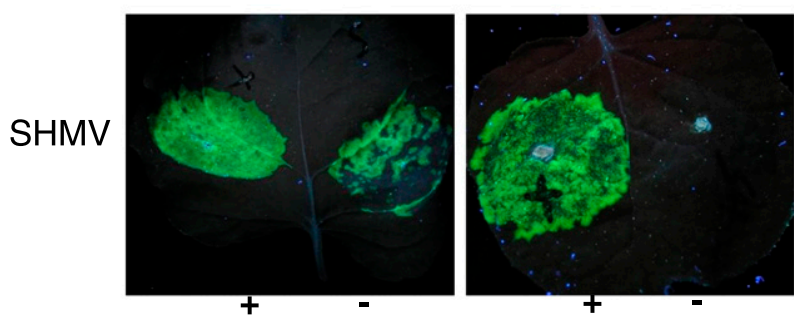

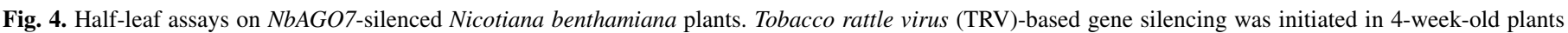

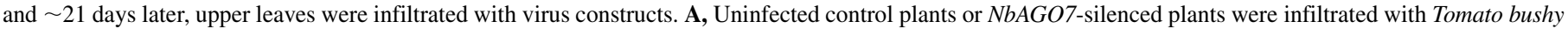

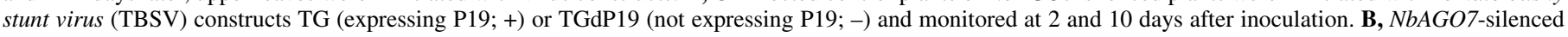

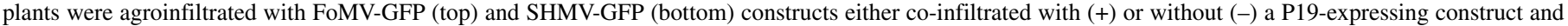
GFP accumulation was monitored 2 and 10 days later. 
$\mathrm{NbAGO1}$ silencing only became evident at least 21 days after initiation of silencing. To determine whether both TRV constructs were systemically spreading through the plants, conventional semiquantitative RT-PCR was performed with extracts of newly formed leaves using primers for detecting the TRV-insert. The results showed that upon coinfiltration of both TRV-NbAGOI and TRV-Sul, only the TRVNbAGO1 accumulated in upper noninoculated plant leaves (Fig. 6B). The experiments were repeated at least three more times with the same outcome, and it did not matter whether each construct was infiltrated separately on individual leaves, or if they were mixed together for simultaneous infiltration of a single leaf.
At about 6 weeks after the initiation of silencing, in the TRVNbAGO1+TRV-Sul infected plants, the conspicuous photobleaching phenotype associated with silencing of $\mathrm{MgChl}$ was observed in new leaves and spread to other leaves starting with the ones showing less deformations associated with $\mathrm{NbAGO1}$ silencing. In about 60 days, the leaf photobleaching associated with $\mathrm{MgChl}$ silencing completely overtook the leaves previously showing the characteristic $\mathrm{NbAGO1}$ silenced phenotype (Fig. 7A). Semiquantitative RT-PCR further confirmed that at day 60, both TRV-NbAGOI and TRV-Sul viral constructs were present in the double co-infiltrations albeit in markedly different quantities (Fig. 7B). However, when TRV-NbAGOl was co-infiltrated
A
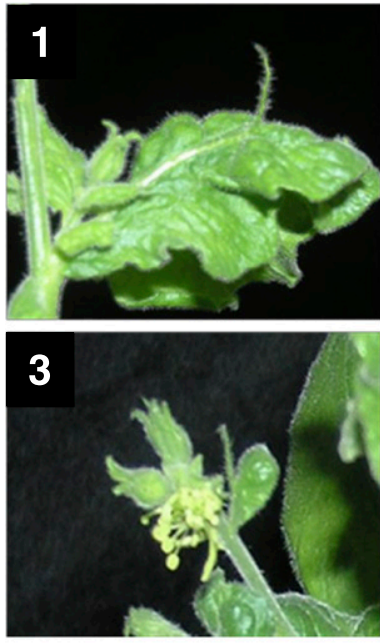

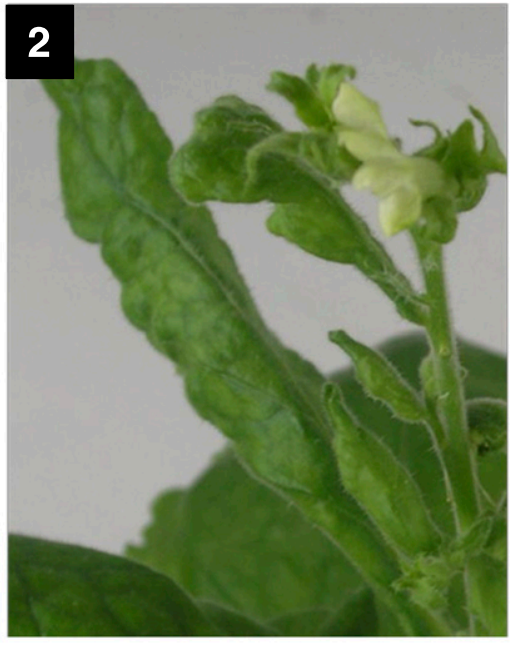

B

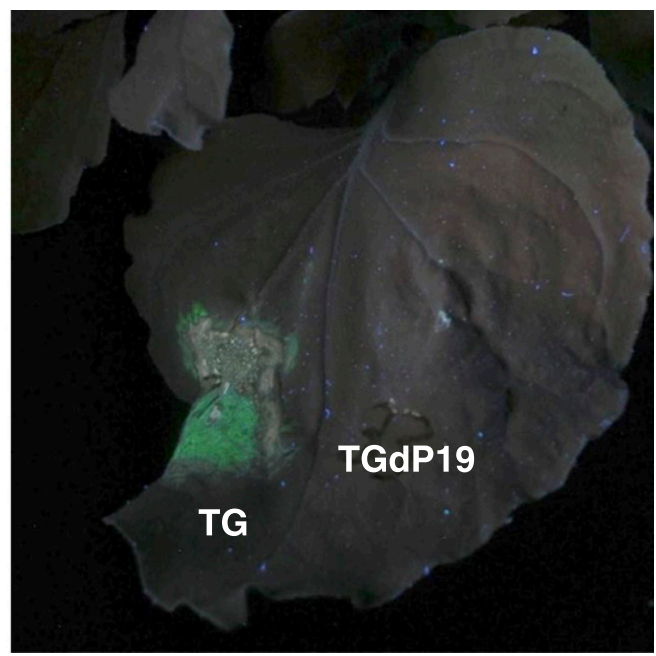

Fig. 5. Developmental effects of silencing NbAGO1 in Nicotiana benthamiana. A, Close-up phenotypes of developmental defects caused by Tobacco rattle virus (TRV)-mediated silencing of NbAGO1. 1) Leaf midrib emerging from leaf surface. 2) Needle-like leaves. 3) Deformed flowers. B, Half-leaf assays on plants simultaneously infected with virus-induced gene silencing (VIGS) vectors targeting NbAGO1 and 2; using GFP chimeric Tomato bushy stunt virus (TBSV) constructs with (TG) or without (TGdP19) the P19 silencing suppressor, inoculated $\sim 21$ days after gene silencing was initiated.

A TRV

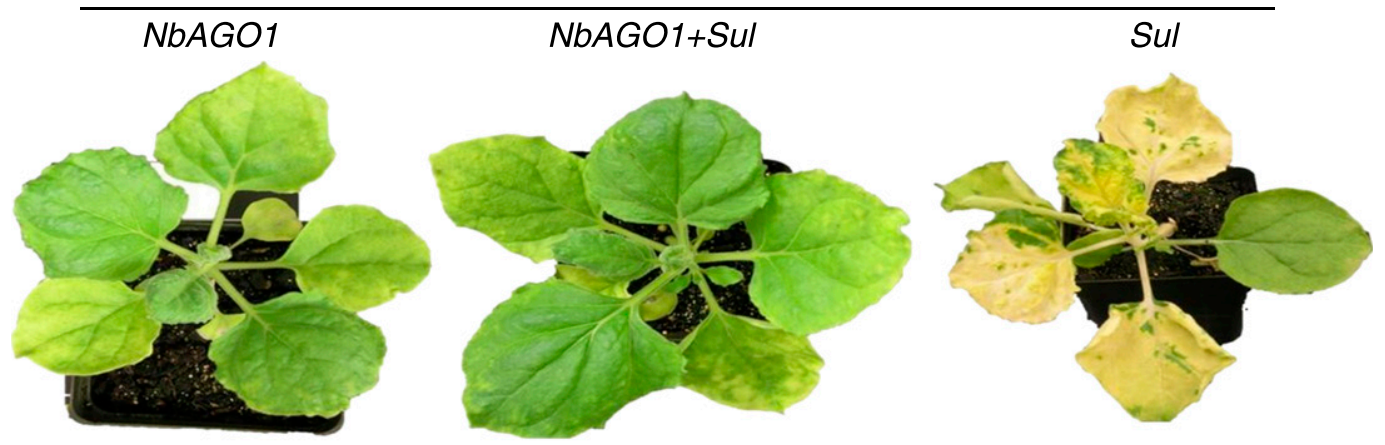

B TRV

$500 \mathrm{bp}$ NbAGO1 Sul $560 \mathrm{bp}$

Fig. 6. Results of co-infiltration of Tobacco rattle virus (TRV)-NbAGO1 and TRV containing a portion of the Magnesium chelatase I cDNA (TRV-Sul) on 4-weekold plants. A, Phenotypes observed 10 days after initiation of gene silencing. B, Viral RNA was isolated from systemically infected leaves and subjected to semiquantitative RT-PCR analysis using TRV multiple cloning site primers to amplify either a $\sim 500$ - or 560-bp insert from TRV-NbAGO1 or TRV-Sul, respectively. 
with TRV-NbAGO2, the TRV-NbAGO2 viral construct had still not accumulated to detectable levels in the newly emerging leaves (Fig. 7B), indicative of its inability to be sustained in the presence of TRV$\mathrm{NbAGO1}$ even at 60 days postinoculation.

\section{DISCUSSION}

N. benthamiana ARGONAUTES and antiviral defense. We have shown that infection of $N$. benthamiana plants with any of the TRV-NbAGO constructs leads to a reduction of target $N b A G O$ gene expression as inferred by associated phenotypes or with qRTPCR. The latter analyses confirmed that each TRV-NbAGO construct indeed down-regulated its targeted homologous mRNA. Furthermore, these tests and many related experiments in the laboratory consistently showed much higher levels of NbAGO4 expression in $N$. benthamiana compared with other $N b A G O s$, as is in agreement with reports for Arabidopsis (Schmid et al. 2005) and $N$. benthamiana (Nakasugi et al. 2013).

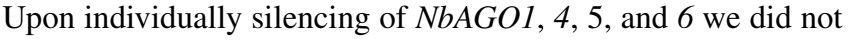
observe an effect on susceptibility of infiltrated leaves for the tested GFP-expressing TBSV, FoMV, and SHMV constructs. Likewise, no increase in susceptibility to these viruses was observed in plants in which $N b A G O 1$ expression was reduced (Fig. 2). On the other

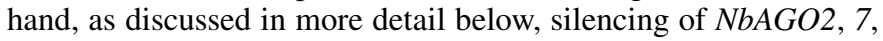
and $5 L$ resulted in different levels of reduced specific ( $N b A G O 2$ and $5 L)$ or general (NbAGO7) antiviral activity, showing that TRVmediated targeting of NbAGOs in this study revealed expected as well as newly discovered antiviral roles.

In initial tests we noticed that in plants infected with TRVNbAGO6 or 7, the mRNA levels of NbAGO1, 2, and $5 L$ were reduced to less than $50 \%$ compared with TRV-00 (data not shown).
Even though this could account for the early general antiviral effect

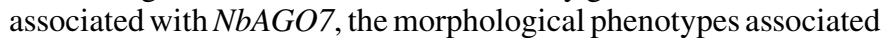

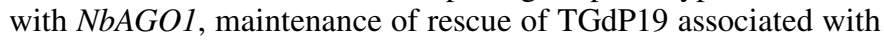
NbAGO2, and minor restorative effects specific for TGdP19 associated with $N b A G O 5 L$, were never observed for plants infected with TRV-NbAGO6 or 7. Thus, any trans-acting effects are not due to off-target silencing but through some undefined cross-talk interactions that may be measurable at the molecular level but do not result in a detectable biological consequence during our virus inoculation studies. Likewise, we have seen similar effects whereby silencing of $\mathrm{NbAGO1}$ may influence expression of other NbAGOs (data not shown), but no discernable phenotype possibly associated with those other NbAGOs was ever evinced. Along those same lines, one could certainly postulate that the effect associated with silencing $N b A G O 5 L$ is due to cross silencing of $\mathrm{NbAGO2}$ but initial qRT-PCR data do not lend support for this notion (data not shown). Therefore, although TRV-mediated silencing of any particular $N b A G O$ may have cascading effects on accumulation of other $N b A G O$ transcripts, such effects seem biologically inconsequential because our studies support a conclusion that the primary biological effect was only associated with silencing of the respective target $N b A G O$. That is, only when

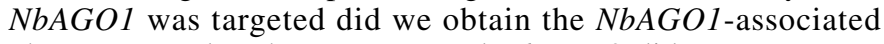
phenotype; only when we targeted $\mathrm{NbAGO2}$ did we see strong effects on TBSV silencing and so on. However, our observations do suggest that further study could provide insights into transacting interactions between $(\mathrm{Nb}) \mathrm{AGO}$ proteins and whether these are relevant in experimental situations where a particular $(\mathrm{Nb})$ AGO is artificially misregulated. Studies to address some of those questions are part of a larger functional genomics project recently initiated.

A

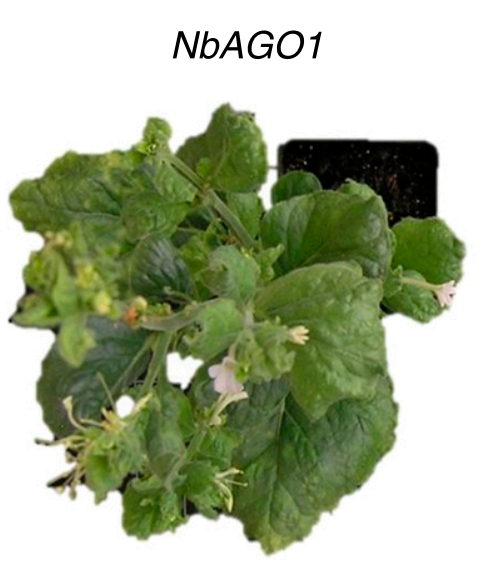

B

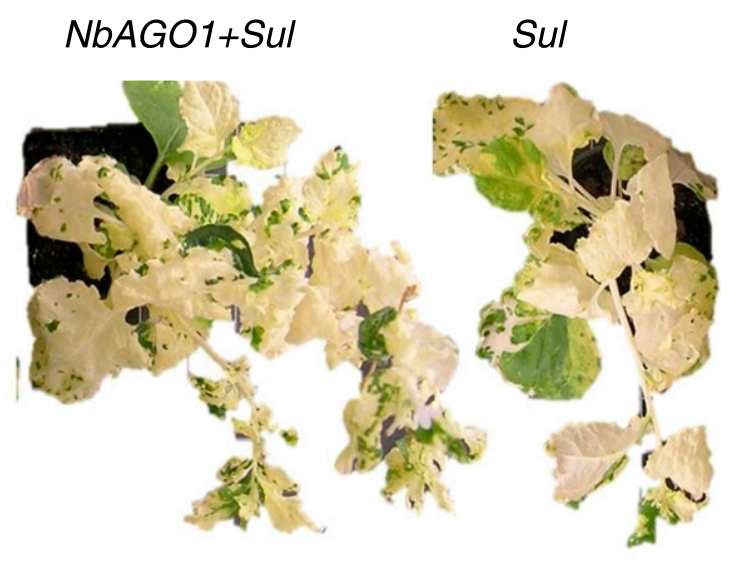

TRV

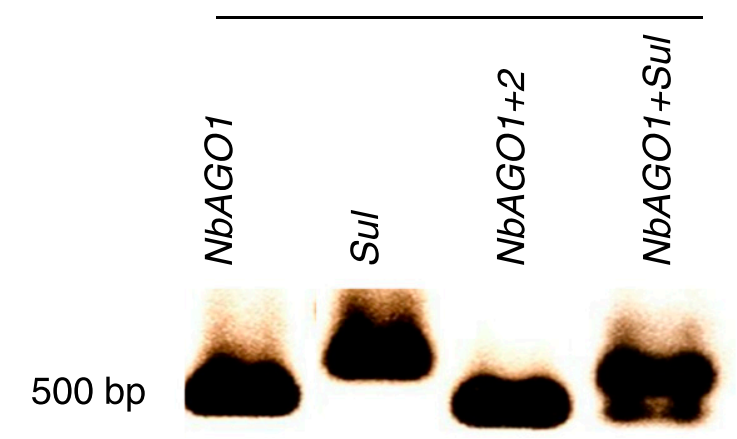

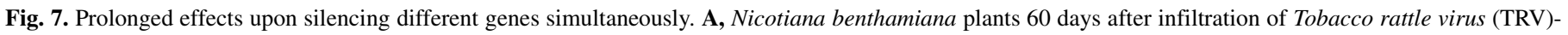

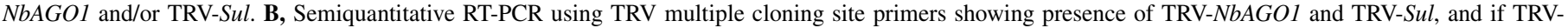
NbAGO2 had accumulated at detectable levels a $~ 620$-bp fragment was expected, as in Figure 1. 
In Arabidopsis, AGO1 is not only involved in mRNA-directed plant development (Baumberger and Baulcombe 2005; Vaucheret 2008; Vaucheret et al. 2006), but also is shown to be important for antiviral defense against suppressor-defective Turnip mosaic virus (TuMV) (Garcia-Ruiz et al. 2015), Cucumber mosaic virus (CMV), members of the family Polerovirus (Baumberger et al. 2007; Bortolamiol et al. 2007, 2008; Morel et al. 2002; Zhang et al. 2006) as well as other viruses (Dzianott et al. 2012). A temperaturedependent symptom recovery against ToRSV was also observed to be associated with $\mathrm{NbAGO1}$ (Ghoshal and Sanfacon 2014). In rice, AGO1 has also been implicated in a broad-based antiviral defense mechanism (Wu et al. 2015). Furthermore, a generally observed response to viral infection is an induction of $A G O 1$ mRNA accumulation (Csorba et al. 2007, 2010; Havelda et al. 2008), as we have also observed in plants infected with TBSV and TMV (Alvarado 2012).

As previously reported (Bhattacharjee et al. 2009; Jones et al. 2006) and confirmed in the present study, the silencing of $\mathrm{NbAGO1}$ caused several developmental defects on the aerial parts of the $N$. benthamiana plant characterized by deformed leaves, misaligned veins, emerged midrib from leaf surface, malformation and

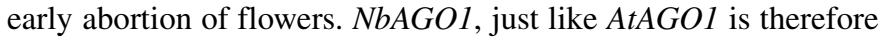
likely critical in the regulation of developmentally related miRNAs and vice versa. Based on this, we expected $N b A G O 1$ to exhibit at the least some general antiviral activity. To our surprise however, as inferred from monitoring virus-associated GFP accumulation in inoculated $N$. benthamiana leaves, in this host reduction of $\mathrm{NbAGO1}$ expression did not foster any enhanced susceptibility to any of the viruses tested, either in presence or absence of a silencing suppressor. If anything, as a general observation we noted that

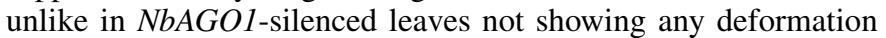
phenotype (Fig. 5B) the leaves that did show the characteristic phenotypes associated with $\mathrm{NbAGO1}$ silencing (Fig. 5A) were more resistant to necrosis and leaf senescence normally caused by accumulation of our virus constructs (data not shown). This is consistent with previous reports showing that agol mutants often show increased resistance against viruses such as TRV, TuMV, and PVX (Brosseau and Moffett 2015; Garcia-Ruiz et al. 2015; Ma et al. 2015), as well as reports showing that silencing or mutation of $A G O 1$ can result in constitutive expression of defense-related genes and enhanced resistance gene responses (Bhattacharjee et al. 2009; Li et al. 2010, 2012; Shivaprasad et al. 2012; Tameling and Baulcombe 2007). We therefore speculate that silencing of $\mathrm{NbAGO1}$ may cause down-regulation of other genes normally involved in the plant defense mechanism associated with cell death, which would explain the limited necrosis observed on $\mathrm{NbAGO1}$ silenced plants despite the massive accumulation of virus. In short, our novel results with $N$. benthamiana show that unlike its homolog in Arabidopsis, NbAGO1 may only have limited antiviral capabilities in $N$. benthamiana leaves, at least for the viruses we tested.

The proteins encoded by ARGONAUTE2, 5, and 7 have previously been implicated in antiviral defense in different plant species. Arabidopsis AGO2 was shown to have potent antiviral activities against TuMV (Garcia-Ruiz et al. 2015), tombusvirus replication in vitro (Schuck et al. 2013), CMV (Wang et al. 2011a), Turnip crinkle virus (TCV) (Harvey et al. 2011; Zhang et al. 2012), TRV (Ma et al. 2015), and PVX (Brosseau and Moffett, 2015; Jaubert et al. 2011). In $N$. benthamiana, NbAGO2 has also been shown to have anti-TBSV activities (Scholthof et al. 2011), as confirmed in the present study, as well as a more general role against wild-type TMV and PVX (Odokonyero et al. 2015). Conversely, in the present study we did not observe any increased susceptibility to non-wild-type suppressor-defective SHMV (Tobamovirus) or FoMV (Potexvirus) GFP-chimeric constructs upon silencing of

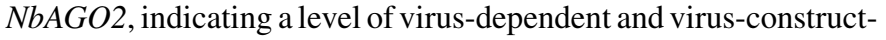
dependent contributions.

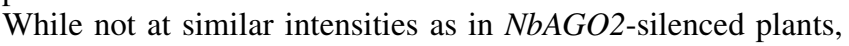
the TBSV construct lacking a silencing suppressor (TGdP19) persistently accumulated GFP in $N b A G O 5 L$-silenced leaves. This was not observed for any of the other tested viruses, once more indicative of the specificity of a given $N b A G O$ virus interaction. Alignments of $N b A G O$ nucleotide sequences show that $N b A G O 5$ and $5 L$ share more than $80 \%$ nucleotide sequence similarity while their protein sequences are over $90 \%$ similar. Genome context analyses revealed that both homologs are adjacent to a gene annotated as encoding VSP41, and the distinction in homologs is probably due to allotetraploidy in $N$. benthamiana. Why VIGS of only one of the homologs (NbAGO5L as seen in Fig. 2) affected antiviral action is not known but it could be related to the fact that the target for NbAGO5 is at the $3^{\prime}$-end, whereas our NbAGO5L target is located toward the $5^{\prime}$-end of the mRNA. Nevertheless, with VIGS NbAGO5 was effectively down-regulated (Fig. 1), suggesting that if there is a positional effect it must be affecting events downstream of the mRNA silencing process. In any case, the similarity of $N b A G O 5 L$ with AtAGO5 would agree with results of a recent study showing antiviral activity associated with AtAGO5 toward PVX (Brosseau and Moffett 2015).

The Arabidopsis AGO7, along with AGO1 and other proteins of the gene-silencing pathway, has been implicated in defense against certain derivatives of TCV (Qu et al. 2008). Our observations indicate that the $N$. benthamiana AGO7 homolog also plays a role in antiviral defense. We detected a consistently early accumulation of GFP in NbAGO7-silenced plants upon infection with suppressordefective TBSV-GFP, SHMV-GFP, and FoMV-GFP chimeric constructs. However, the GFP accumulation later dissipated, indicating that the antiviral role of $\mathrm{NbAGO7}$ is probably limited to initial stages after which it becomes overshadowed by activities of one or more of the other NbAGOs. This is consistent with a proposed minor role of AGO7 in defense against suppressor-defective TuMV (Garcia-Ruiz et al. 2015).

Although genetic and biochemical evidence support a role for Arabidopsis AGO4 in antiviral defense against several RNA (Bhattacharjee et al. 2009; Brosseau et al. 2016; Hamera et al. 2012; Ma et al. 2015) and DNA viruses (Raja et al. 2008, 2014), our system failed to show a direct role for both $\mathrm{NbAGO4}$ and 6 in antiviral silencing defense against the tested viruses. It is worth noting that NbAGO6 has some identity with a gene recently annotated as $\mathrm{NbAGO16}$ that was not included in this study.

Despite having tested only a few viruses, the role of specific $N b A G O$ s in antiviral defense and more specifically, the distinct interaction between particular $N b A G O$ s and a given virus clearly surfaces. It is also quite evident that even though there are some striking similarities between Arabidopsis and $N$. benthamiana AGO homologs, they do not always play the same regulatory and/or antiviral defense roles. In this context, one is tempted to further explore the molecular basis for the observation that the prominent antiviral role for $A t A G O 1$ has not yet surfaced in this work or our previous studies for $\mathrm{NbAGO1}$ (Odokonyero et al. 2015; Scholthof et al. 2011). For instance, it is relevant to note that there are two copies of NbAGO1 that are both silenced by TRV-NbAGO1 (Jones et al. 2006), and even though this has no effect on silencing against TBSV, as mentioned earlier, similar experiments did show that $\mathrm{NbAGO1}$ is involved in antiviral defense against ToRSV (Ghoshal and Sanfacon 2014). Rather contrary to this virus-specific situation for $N$. benthamiana during in vivo experiments, it was reported that most AtAGOs, especially those with enhanced slicer activity (e.g., AtAGOl and 2) had broad nonspecific in vitro antiviral activities (including against TBSV) in $N$. tabacum cytoplasmic extracts (Schuck et al. 2013). Even without considering that Arabidopsis (natively expressing AtAGO1) is not a host for TBSV, the comparative results suggest that certain specific results obtained during in vivo assays are not recapitulated with apparently less specific in vitro tests.

In summary, even though the lack of antiviral activity for $\mathrm{NbAGO1}$ is different from that observed for AGOl in Arabidopsis,

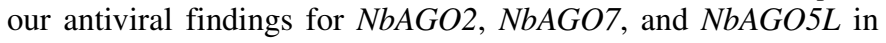


$N$. benthamiana are reminiscent of the identified antiviral roles demonstrated for AtAGO2 (Carbonell et al. 2012; Garcia-Ruiz et al. 2015; Harvey et al. 2011; Jaubert et al. 2011; Ma et al. 2015; Schuck et al. 2013; Wang et al. 2011b; Zhang et al. 2012), AtAGO7 (GarciaRuiz et al. 2015; Qu et al. 2008), and AtAGO5 (Brosseau and Moffett 2015; Garcia-Ruiz et al. 2015; Takeda et al. 2008). Furthermore, recent analyses have shown that in Arabidopsis all AGO proteins have the potential to target viral or virus-like RNAs (Brosseau and Moffett 2015; Minoia et al. 2014) but the requirement for different AGOs in targeting specific viruses may be affected by access to viral RNA, targeting of specific AGO proteins by VSRs as well as spatiotemporal expression patterns of $A G O$ genes. The findings in our study agree with such postulated dynamic and functionally (partial) redundant roles of $(\mathrm{Nb}) \mathrm{AGOs}$ to optimize antiviral defenses under different circumstances.

Dominant effects upon silencing plants with TRV$\mathrm{NbAGO1}$. Inoculations of $N$. benthamiana with individual TRV$\mathrm{NbAGO}$ constructs reveal similar levels of accumulation for each (Fig. 1A). However, our observations upon simultaneous coinoculation with various TRV vector constructs indicate that this leads to an uneven systemic distribution in presence of TRVNbAGOI (Figs. 6 and 7). It could be that silencing of any $N b A G O$ other than $\mathrm{NbAGO1}$ could also impose dominant effects on some or all other $N b A G O s$ but this was not investigated. The explanation or the mechanism behind these dominant cross-protection type of effects associated with TRV-NbAGOI infections is unclear. It has been shown previously that in Arabidopsis AGO1 seems to be required for VIGS (Ma et al. 2015), but the present study in N. benthamiana shows that down-regulation of $\mathrm{NbAGO1}$ is readily achieved by infection with TRV-NbAGO1, suggesting that VIGS is still operational but it could affect other constructs differentially.

Furthermore, even though it needs to be further studied, we have observed that expression levels of $\mathrm{NbAGO1}$ can influence expression levels of some other NbAGOs (data not shown), as has also been demonstrated in Arabidopsis (Allen et al. 2005), which could influence the accumulation of co-infiltrated TRV constructs differentially. As such, there is a possibility that down-regulation of $\mathrm{NbAGO1}$ expression in itself could differentially affect the ability of the plant machinery to silence expression of other genes. Therefore, whether the enigmatic dominant effect we observed upon silencing plants with TRV-NbAGO1 is directly a consequence of down-

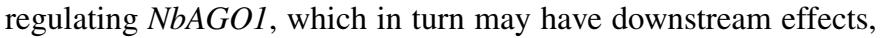
needs to be addressed in future studies.

Another contributing factor could be related to insert size in the TRV vector. The effect of insert size on the development of symptoms caused by using TRV as a vector in tomato (Solanum lycopersicum) has been documented in a study showing that the empty TRV vector caused far more extensive symptoms of virus infection than other silencing constructs (Wu et al. 2011) suggesting that the viral systemic spread and symptom development might be influenced by the size of the viral vector. Similarly, our TRV-NbAGO1 with a smaller $(\sim 425 \mathrm{bp})$ insert could potentially outcompete TRV-NbAGO2 that contains a longer insert ( $\sim 600 \mathrm{bp})$. However, this does not explain why the TRV-NbAGO1 viral construct would outcompete other smaller constructs such as TRV-NbAGO5 and 6 , and even more surprisingly, the empty vector TRV-00 (data not shown). It certainly does not agree with the fact that TRV-Sul with a smaller insert than $T R V-N b A G O 1$ is initially outcompeted by the latter (Fig. 6).

If the size of the insert is not a definitive predictor, what other insert-dependent feature could serve as a possible explanation for the dominant effect of the TRV-NbAGO1 viral construct? Possible answers may lie in long-range intramolecular RNA-RNA interactions. RNA viruses have been traditionally viewed as linearized sequences or localized structures such as hairpins, whereas it is now known that functional viral RNA elements form long-range RNA-RNA interactions spanning significant distances (Diviney et al. 2008; Hu et al. 2007; Miller and White 2006; Serrano et al. 2006; Song et al. 2008) which may regulate both translation and transcription. For instance, TBSV replication requires a long-range RNA-based interaction spanning approximately 3,000 nucleotides and analyses suggest that the discontinuous RNA platform formed by the interaction facilitates efficient assembly of the viral RNA replicase (Wu et al. 2009a). A functional viral RNA genome is therefore a three-dimensional molecule with multiple interactions occurring which may hinder or facilitate virus replication or movement. It is therefore possible that the insertion of the approximately 420-bp NbAGOl sequences into the TRV vector may have modified its three-dimensional structure to fold in a way that favors replication and/or movement giving it a competitive edge over the other constructs and in effect cross-protect against other constructs.

Even though the above-mentioned possibilities need to be investigated in future studies, at present we can conclude that although it may be possible to concurrently silence multiple $N$. benthamiana $A G O$ genes using the TRV vector system, as noted in this study it can take months to become established. This, in combination with the fact that the silencing by, or mere presence of, one TRV construct may influence the performance of another in a very unpredictable manner suggests caution is needed with such an approach.

\section{ACKNOWLEDGMENTS}

We thank C. Kearny for SHMV-GFP and FoMV-GFP expressing vectors, A. Baker for assistance with the co-infiltrations of different TRV-NbAGO constructs, J. Vega-Arreguin for identifying $N b A G O$ sequences in the databases, and C. Brosseau for helping with the NbAGO5L identification, and the Department of Biology at Texas A\&M University for generously allowing us to use their real-time PCR facility. We thank V. Alvarado and K.-B. G. Scholthof and her research group for the helpful comments at various stages through the study and during manuscript preparation. The work was possible through funding from Texas AgriLife Research (TEX08387), awards from USDA-NIFA-AFRI 2012-67013-19397 and 2015-67013-22916, and support by the TAMU AFS Development Leave Program.

\section{LITERATURE CITED}

Alazem, M., He, M. H., Moffett, P., and Lin, N. S. 2017. Abscisic acid induces resistance against Bamboo mosaic virus through Argonaute2 and 3. Plant Physiol. 174:339-355.

Allen, E., Xie, Z., Gustafson, A. M., and Carrington, J. C. 2005. MicroRNAdirected phasing during trans-acting siRNA biogenesis in plants. Cell 121: 207-221

Alvarado, V. Y. 2012. Argonaute and antiviral silencing in Nicotiana benthamiana. Plant Biology. American Society of Plant Biologist, Austin, TX.

Bai, M., Yang, G.-S., Chen, W.-T., Mao, Z.-C., Kang, H.-X., Chen, G.-H., Yang, Y.-H., and Xie, B.-Y. 2012. Genome-wide identification of Dicerlike, Argonaute and RNA-dependent RNA polymerase gene families and their expression analyses in response to viral infection and abiotic stresses in Solanum lycopersicum. Gene 501:52-62.

Baumberger, N., and Baulcombe, D. C. 2005. Arabidopsis ARGONAUTE1 is an RNA slicer that selectively recruits microRNAs and short interfering RNAs. Proc. Natl. Acad. Sci. USA 102:11928-11933.

Baumberger, N., Tsai, C. H., Lie, M., Havecker, E., and Baulcombe, D. C. 2007. The polerovirus silencing suppressor PO targets Argonaute proteins for degradation. Curr. Biol. 17:1609-1614.

Bezier, A., Lambert, B., and Baillieul, F. 2002. Study of defense-related gene expression in grapevine leaves and berries infected with Botrytis cinerea. Eur. J. Plant Pathol. 108:111-120.

Bhattacharjee, S., Zamora, A., Azhar, M. T., Sacco, M. A., Lambert, L. H., and Moffett, P. 2009. Virus resistance induced by NB-LRR proteins involves Argonaute4-dependent translational control. Plant J. 58:940-951.

Bohmert, K., Camus, I., Bellini, C., Bouchez, D., Caboche, M., and Benning, C. 1998. AGO1 defines a novel locus of Arabidopsis controlling leaf development. EMBO J. 17:170-180.

Bortolamiol, D., Pazhouhandeh, M., Marrocco, K., Genschik, P., and Ziegler-Graff, V. 2007. The Polerovirus F box protein P0 targets Argonaute1 to suppress RNA silencing. Curr. Biol. 17:1615-1621.

Bortolamiol, D., Pazhouhandeh, M., and Ziegler-Graff, V. 2008. Viral suppression of RNA silencing by destabilisation of Argonaute 1. Plant Signal. Behav. 3:657-659. 
Brosseau, C., El Oirdi, M., Adurogbangba, A., Ma, X., and Moffett, P. 2016. Antiviral defense involves AGO4 in an Arabidopsis-Potexvirus interaction. Mol. Plant-Microbe Interact. 29:878-888.

Brosseau, C., and Moffett, P. 2015. Functional and genetic analysis identify a role for Arabidopsis Argonaute5 in antiviral RNA silencing. Plant Cell 27: $1742-1754$.

Bustin, S. A. 2002. Quantification of mRNA using real-time reverse transcription PCR (RT-PCR): Trends and problems. J. Mol. Endocrinol. 29: 23-39.

Bustin, S. A. 2010. Why the need for qPCR publication guidelines? The case for MIQE. Methods 50:217-226.

Bustin, S. A., Benes, V., Garson, J. A., Hellemans, J., Huggett, J., Kubista, M., Mueller, R., Nolan, T., Pfaffl, M. W., Shipley, G. L., Vandesompele, J., and Wittwer, C. T. 2009. The MIQE guidelines: Minimum information for publication of quantitative real-time PCR experiments. Clin. Chem. 55:611-622.

Carbonell, A., and Carrington, J. C. 2015. Antiviral roles of plant Argonautes. Curr. Opin. Plant Biol. 27:111-117.

Carbonell, A., Fahlgren, N., Garcia-Ruiz, H., Gilbert, K. B., Montgomery, T. A., Nguyen, T., Cuperus, J. T., and Carrington, J. C. 2012. Functional analysis of three Arabidopsis Argonautes using slicer-defective mutants. Plant Cell 24:3613-3629.

Carmell, M. A., Xuan, Z., Zhang, M. Q., and Hannon, G. J. 2002. The Argonaute family: Tentacles that reach into RNAi, developmental control, stem cell maintenance, and tumorigenesis. Genes Dev. 16:2733-2742.

Clemente, T. 2006. Nicotiana (Nicotiana tabacum, Nicotiana benthamiana). Methods Mol. Biol. 343:143-154.

Csorba, T., Bovi, A., Dalmay, T., and Burgyan, J. 2007. The p122 subunit of Tobacco mosaic virus replicase is a potent silencing suppressor and compromises both small interfering RNA- and microRNA-mediated pathways. J. Virol. 81:11768-11780.

Csorba, T., Lozsa, R., Hutvagner, G., and Burgyan, J. 2010. Polerovirus protein P0 prevents the assembly of small RNA-containing RISC complexes and leads to degradation of Argonaute1. Plant J. 62:463-472.

Diviney, S., Tuplin, A., Struthers, M., Armstrong, V., Elliott, R. M., Simmonds, P., and Evans, D. J. 2008. A Hepatitis C virus cis-acting replication element forms a long-range RNA-RNA interaction with upstream RNA sequences in NS5B. J. Virol. 82:9008-9022.

Dong, J., Kim, S. T., and Lord, E. M. 2005. Plantacyanin plays a role in reproduction in Arabidopsis. Plant Physiol. 138:778-789.

Dzianott, A., Sztuba-Solinska, J., and Bujarski, J. J. 2012. Mutations in the antiviral RNAi defense pathway modify Brome mosaic virus RNA recombinant profiles. Mol. Plant-Microbe Interact. 25:97-106.

Edgar, R. C. 2004. MUSCLE: Multiple sequence alignment with high accuracy and high throughput. Nucleic Acids Res. 32:1792-1797.

Fang, X., and Qi, Y. 2016. RNAi in plants: An Argonaute-centered view. Plant Cell 28:272-285.

Fujita, M., Horiuchi, Y., Ueda, Y., Mizuta, Y., Kubo, T., Yano, K., Yamaki, S., Tsuda, K., Nagata, T., Niihama, M., Kato, H., Kikuchi, S., Hamada, K., Mochizuki, T., Ishimizu, T., Iwai, H., Tsutsumi, N., and Kurata, N. 2010. Rice expression atlas in reproductive development. Plant Cell Physiol. 51: 2060-2081.

Garcia-Ruiz, H., Carbonell, A., Hoyer, J. S., Fahlgren, N., Gilbert, K. B., Takeda, A., Giampetruzzi, A., Garcia Ruiz, M. T., McGinn, M. G., Lowery, N., Martinez Baladejo, M. T., and Carrington, J. C. 2015. Roles and programming of Arabidopsis argonaute proteins during Turnip mosaic virus infection. PLoS Pathog. 11:e1004755.

Ghoshal, B., and Sanfacon, H. 2014. Temperature-dependent symptom recovery in Nicotiana benthamiana plants infected with tomato ringspot virus is associated with reduced translation of viral RNA2 and requires Argonaute1. Virology 456-457:188-197.

Goodin, M. M., Zaitlin, D., Naidu, R. A., and Lommel, S. A. 2008. Nicotiana benthamiana: Its history and future as a model for plant-pathogen interactions. Mol. Plant-Microbe Interact. 21:1015-1026.

Hamera, S., Song, X., Su, L., Chen, X., and Fang, R. 2012. Cucumber mosaic virus suppressor $2 \mathrm{~b}$ binds to AGO4-related small RNAs and impairs AGO4 activities. Plant J. 69:104-115.

Harvey, J. J., Lewsey, M. G., Patel, K., Westwood, J., Heimstadt, S., Carr, J. P., and Baulcombe, D. C. 2011. An antiviral defense role of AGO2 in plants. PLoS One 6:e14639.

Havecker, E. R., Wallbridge, L. M., Hardcastle, T. J., Bush, M. S., Kelly, K. A., Dunn, R. M., Schwach, F., Doonan, J. H., and Baulcombe, D. C. 2010. The Arabidopsis RNA-directed DNA methylation argonautes functionally diverge based on their expression and interaction with target loci. Plant Cell 22:321-334

Havelda, Z., Varallyay, E., Valoczi, A., and Burgyan, J. 2008. Plant virus infection-induced persistent host gene downregulation in systemically infected leaves. Plant J. 55:278-288.

Hock, J., and Meister, G. 2008. The Argonaute protein family. Genome Biol. 9:210.
Hu, B., Pillai-Nair, N., and Hemenway, C. 2007. Long-distance RNA-RNA interactions between terminal elements and the same subset of internal elements on the Potato virus $X$ genome mediate minus- and plus-strand RNA synthesis. RNA 13:267-280.

Hutvagner, G., and Simard, M. J. 2008. Argonaute proteins: Key players in RNA silencing. Nat. Rev. Mol. Cell Biol. 9:22-32.

Itoh, J., Nonomura, K., Ikeda, K., Yamaki, S., Inukai, Y., Yamagishi, H., Kitano, H., and Nagato, Y. 2005. Rice plant development: From zygote to spikelet. Plant Cell Physiol. 46:23-47.

Jaubert, M., Bhattacharjee, S., Mello, A. F., Perry, K. L., and Moffett, P. 2011. Argonaute 2 mediates RNA-silencing antiviral defenses against Potato virus $X$ in Arabidopsis. Plant Physiol. 156:1556-1564.

Jones, L., Keining, T., Eamens, A., and Vaistij, F. E. 2006. Virus-induced gene silencing of argonaute genes in Nicotiana benthamiana demonstrates that extensive systemic silencing requires Argonaute1-like and Argonaute4-like genes. Plant Physiol. 141:598-606.

Kataoka, Y., Takeichi, M., and Uemura, T. 2001. Developmental roles and molecular characterization of a Drosophila homologue of Arabidopsis Argonaute1, the founder of a novel gene superfamily. Genes Cells 6: 313-325.

Kim, J. K., Gabel, H. W., Kamath, R. S., Tewari, M., Pasquinelli, A., Rual, J. F., Kennedy, S., Dybbs, M., Bertin, N., Kaplan, J. M., Vidal, M., and Ruvkun, G. 2005. Functional genomic analysis of RNA interference in C. elegans. Science 308:1164-1167.

Kim, K. W., Eamens, A. L., and Waterhouse, P. M. 2011. RNA processing activities of the Arabidopsis Argonaute protein family. Page 248 in: RNA Processing. P. Grabowski, ed. InTech Web.org, University of Pittsburg.

Langer, K., Ache, P., Geiger, D., Stinzing, A., Arend, M., Wind, C., Regan, S., Fromm, J., and Hedrich, R. 2002. Poplar potassium transporters capable of controlling $\mathrm{K}(+)$ homeostasis and $\mathrm{K}(+)$-dependent xylogenesis. Plant J. 32: 997-1009.

Li, F., Pignatta, D., Bendix, C., Brunkard, J. O., Cohn, M. M., Tung, J., Sun, H., Kumar, P., and Baker, B. 2012. MicroRNA regulation of plant innate immune receptors. Proc. Natl. Acad. Sci. USA 109:1790-1795.

Li, Y., Zhang, Q., Zhang, J., Wu, L., Qi, Y., and Zhou, J.-M. 2010. Identification of microRNAs involved in pathogen-associated molecular patterntriggered plant innate immunity. Plant Physiol. 152:2222-2231.

Liu, Z., and Kearney, C. M. 2010a. An efficient Foxtail mosaic virus vector system with reduced environmental risk. BMC Biotechnol. 10:88.

Liu, Z., and Kearney, C. M. 2010b. A tobamovirus expression vector for agroinfection of legumes and Nicotiana. J. Biotechnol. 147:151-159.

Ma, X., Nicole, M. C., Meteignier, L. V., Hong, N., Wang, G., and Moffett, P. 2015. Different roles for RNA silencing and RNA processing components in virus recovery and virus-induced gene silencing in plants. J. Exp. Bot. 66: 919-932.

Manavella, P. A., Weigel, D., and Wu, L. 2011. Argonaute10 as a miRNA locker. Cell 145:173-174.

Maunoury, N., and Vaucheret, H. 2011. AGO1 and AGO2 act redundantly in miR408-mediated plantacyanin regulation. PLoS One 6:e28729.

Miller, W. A., and White, K. A. 2006. Long-distance RNA-RNA interactions in plant virus gene expression and replication. Annu. Rev. Phytopathol. 44: 447-467.

Minoia, S., Carbonell, A., Di Serio, F., Gisel, A., Carrington, J. C., Navarro, B., and Flores, R. 2014. Specific argonautes selectively bind small RNAs derived from potato spindle tuber viroid and attenuate viroid accumulation in vivo. J. Virol. 88:11933-11945.

Morel, J. B., Godon, C., Mourrain, P., Beclin, C., Boutet, S., Feuerbach, F., Proux, F., and Vaucheret, H. 2002. Fertile hypomorphic Argonaute (ago1) mutants impaired in post-transcriptional gene silencing and virus resistance. Plant Cell 14:629-639.

Nakasugi, K., Crowhurst, R. N., Bally, J., Wood, C. C., Hellens, R. P., and Waterhouse, P. M. 2013. De novo transcriptome sequence assembly and analysis of RNA silencing genes of Nicotiana benthamiana. PLoS One 8: e59534.

Nonomura, K., Morohoshi, A., Nakano, M., Eiguchi, M., Miyao, A., Hirochika, H., and Kurata, N. 2007. A germ cell specific gene of the Argonaute family is essential for the progression of premeiotic mitosis and meiosis during sporogenesis in rice. Plant Cell 19:2583-2594.

Odokonyero, D., Mendoza, M. R., Alvarado, V. Y., Zhang, J., Wang, X., and Scholthof, H. B. 2015. Transgenic down-regulation of argonaute 2 expression in Nicotiana benthamiana interferes with several layers of antiviral defenses. Virology 486:209-218.

Papenbrock, J., Mock, H. P., Tanaka, R., Kruse, E., and Grimm, B. 2000. Role of magnesium chelatase activity in the early steps of the tetrapyrrole biosynthetic pathway. Plant Physiol. 122:1161-1169.

Pfaffl, M. W., and Hageleit, M. 2001. Validities of mRNA quantification using recombinant RNA and recombinant DNA external calibration curves in real-time RT-PCR. Biotechnol. Lett. 23:275-282. 
Qian, Y., Cheng, Y., Cheng, X., Jiang, H., Zhu, S., and Cheng, B. 2011. Identification and characterization of Dicer-like, Argonaute and RNAdependent RNA polymerase gene families in maize. Plant Cell Rep. 30: 1347-1363.

Qiu, W., Park, J. W., and Scholthof, H. B. 2002. Tombusvirus p19-mediated suppression of virus-induced gene silencing is controlled by genetic and dosage features that influence pathogenicity. Mol. Plant-Microbe Interact. 15:269-280.

Qu, F., Ye, X., and Morris, T. J. 2008. Arabidopsis DRB4, AGO1, AGO7, and RDR6 participate in a DCL4-initiated antiviral RNA silencing pathway negatively regulated by DCL1. Proc. Natl. Acad. Sci. USA 105: $14732-14737$

Raghavan, V. 1988. Anther and pollen development in rice (Oryza sativa). Am. J. Bot. 75:183-196.

Raja, P., Jackel, J. N., Li, S., Heard, I. M., and Bisaro, D. M. 2014. Arabidopsis double-stranded RNA binding protein DRB3 participates in methylationmediated defense against geminiviruses. J. Virol. 88:2611-2622.

Raja, P., Sanville, B. C., Buchmann, R. C., and Bisaro, D. M. 2008. Viral genome methylation as an epigenetic defense against geminiviruses. J. Virol. 82:8997-9007.

Ratcliff, F., Martin-Hernandez, A. M., and Baulcombe, D. C. 2001. Tobacco rattle virus as a vector for analysis of gene function by silencing. Plant $\mathrm{J}$. 25:237-245.

Schmid, M., Davison, T. S., Henz, S. R., Pape, U. J., Demar, M., Vingron, M., Scholkopf, B., Weigel, D., and Lohmann, J. U. 2005. A gene expression map of Arabidopsis thaliana development. Nat. Genet. 37:501-506.

Scholthof, H. B., Alvarado, V. Y., Vega-Arreguin, J. C., Ciomperlik, J., Odokonyero, D., Brosseau, C., Jaubert, M., Zamora, A., and Moffett, P. 2011. Identification of an Argonaute for antiviral RNA silencing in Nicotiana benthamiana. Plant Physiol. 156:1548-1555.

Schuck, J., Gursinsky, T., Pantaleo, V., Burgyan, J., and Behrens, S. E. 2013. AGO/RISC-mediated antiviral RNA silencing in a plant in vitro system. Nucleic Acids Res. 41:5090-5103.

Serrano, P., Pulido, M. R., Saiz, M., and Martinez-Salas, E. 2006. The 3' end of the foot-and-mouth disease virus genome establishes two distinct longrange RNA-RNA interactions with the $5^{\prime}$ end region. J. Gen. Virol. 87: 3013-3022.

Shivaprasad, P. V., Chen, H. M., Patel, K., Bond, D. M., Santos, B. A., and Baulcombe, D. C. 2012. A microRNA superfamily regulates nucleotide binding site-leucine-rich repeats and other mRNAs. Plant Cell 24: 859-874.

Sigova, A., Rhind, N., and Zamore, P. D. 2004. A single Argonaute protein mediates both transcriptional and posttranscriptional silencing in Schizosaccharomyces pombe. Genes Dev. 18:2359-2367.

Song, B.-H., Yun, S.-I., Choi, Y.-J., Kim, J.-M., Lee, C.-H., and Lee, Y.-M. 2008. A complex RNA motif defined by three discontinuous 5-nucleotidelong strands is essential for Flavivirus RNA replication. RNA 14: 1791-1813.

Sparkes, I. A., Runions, J., Kearns, A., and Hawes, C. 2006. Rapid, transient expression of fluorescent fusion proteins in tobacco plants and generation of stably transformed plants. Nat. Protoc. 1:2019-2025.

Takeda, A., Iwasaki, S., Watanabe, T., Utsumi, M., and Watanabe, Y. 2008. The mechanism selecting the guide strand from small RNA duplexes is different among argonaute proteins. Plant Cell Physiol. 49:493-500.

Tameling, W. I. L., and Baulcombe, D. C. 2007. Physical association of the NB-LRR resistance protein $\mathrm{Rx}$ with a ran GTPase-activating protein is required for extreme resistance to Potato virus X. Plant Cell 19: 1682-1694.

Taylor, S., Wakem, M., Dijkman, G., Alsarraj, M., and Nguyen, M. 2010. A practical approach to RT-qPCR-publishing data that conform to the MIQE guidelines. Methods 50:S1-S5.

Teo, C. H., Pui, H. P., Othman, R. Y., and Harikrishna, J. A. 2011. Comparative analysis of Argonaute gene sequences in bananas (Musa sp.) shows conserved species-specific Ago-7 PIWI domains. Genet. Resour. Crop Evol. 58:713-725.
Thomas, C., Meyer, D., Wolff, M., Himber, C., Alioua, M., and Steinmetz, A. 2003. Molecular characterization and spatial expression of the sunflower ABP1 gene. Plant Mol. Biol. 52:1025-1036.

Vaucheret, H. 2008. Plant argonautes. Trends Plant Sci. 13:350-358.

Vaucheret, H., Mallory, A. C., and Bartel, D. P. 2006. AGO1 homeostasis entails coexpression of MIR168 and AGO1 and preferential stabilization of miR168 by AGO1. Mol. Cell 22:129-136.

Wang, H., Zhang, X., Liu, J., Kiba, T., Woo, J., Ojo, T., Hafner, M., Tuschl, T., Chua, N. H., and Wang, X. J. 2011a. Deep sequencing of small RNAs specifically associated with Arabidopsis AGO1 and AGO4 uncovers new AGO functions. Plant J. 67:292-304.

Wang, X. B., Jovel, J., Udomporn, P., Wang, Y., Wu, Q. F., Li, W. X., Gasciolli, V., Vaucheret, H., and Ding, S. W. 2011b. The 21-nucleotide, but not 22-nucleotide, viral secondary small interfering RNAs direct potent antiviral defense by two cooperative Argonautes in Arabidopsis thaliana. Plant Cell 23:1625-1638.

Williams, R. W., and Rubin, G. M. 2002. Argonaute1 is required for efficient RNA interference in Drosophila embryos. Proc. Natl. Acad. Sci. USA 99: 6889-6894.

Wu, B., Pogany, J., Na, H., Nicholson, B. L., Nagy, P. D., and White, K. A. 2009a. A discontinuous RNA platform mediates RNA virus replication: Building an integrated model for RNA-based regulation of viral processes. PLoS Pathog. 5:e1000323.

Wu, C. J., Jia, L. L., and Goggin, F. 2011. The reliability of virus-induced gene silencing experiments using Tobacco rattle virus in tomato is influenced by the size of the vector control. Mol. Plant Pathol. 12:299-305.

Wu, J., Yang, Z., Wang, Y., Zheng, L., Ye, R., Ji, Y., Zhao, S., Ji, S., Liu, R., Xu, L., Zheng, H., Zhou, Y., Zhang, X., Cao, X., Xie, L., Wu, Z., Qi, Y., and Li, Y. 2015. Viral-inducible Argonaute18 confers broad-spectrum virus resistance in rice by sequestering a host microRNA. eLife 4:e05733.

Wu, L., Zhang, Q., Zhou, H., Ni, F., Wu, X., and Qi, Y. 2009b. Rice microRNA effector complexes and targets. Plant Cell 21:3421-3435.

Wydro, M., Kozubek, E., and Lehmann, P. 2006. Optimization of transient Agrobacterium-mediated gene expression system in leaves of Nicotiana benthamiana. Acta Biochim. Pol. 53:289-298.

Zhai, L., Sun, W., Zhang, K., Jia, H., Liu, L., Liu, Z., Teng, F., and Zhang, Z. 2014. Identification and characterization of Argonaute gene family and meiosis-enriched Argonaute during sporogenesis in maize. J. Integr. Plant Biol. 56:1042-1052.

Zhang, X., Yuan, Y.-R., Pei, Y., Lin, S.-S., Tuschl, T., Patel, D. J., and Chua, N.-H. 2006. Cucumber mosaic virus-encoded 2b suppressor inhibits Arabidopsis Argonaute1 cleavage activity to counter plant defense. Genes Dev. 20:3255-3268.

Zhang, X., Zhang, X., Singh, J., Li, D., and Qu, F. 2012. Temperaturedependent survival of Turnip crinkle virus-infected Arabidopsis plants relies on an RNA silencing-based defense that requires dc12, AGO2, and HEN1. J. Virol. 86:6847-6854.

Zhang, X., Zhao, H., Gao, S., Wang, W. C., Katiyar-Agarwal, S., Huang, H. D., Raikhel, N., and Jin, H. 2011. Arabidopsis Argonaute 2 regulates innate immunity via miRNA393(*)-mediated silencing of a Golgi-localized SNARE gene, MEMB12. Mol. Cell 42:356-366.

Zhao, K., Zhao, H., Chen, Z., Feng, L., Ren, J., Cai, R., and Xiang, Y. 2015. The Dicer-like, Argonaute and RNA-dependent RNA polymerase gene families in Populus trichocarpa: Gene structure, gene expression, phylogenetic analysis and evolution. J. Genet. 94:317-321.

Zheng, X., Zhu, J., Kapoor, A., and Zhu, J.-K. 2007. Role of Arabidopsis AGO6 in siRNA accumulation, DNA methylation and transcriptional gene silencing. EMBO J. 26:1691-1701.

Zhou, Y., and Ni, M. 2010. Short hypocotyl under blue1 truncations and mutations alter its association with a signaling protein complex in Arabidopsis. Plant Cell 22:703-715.

Zhu, H., Hu, F., Wang, R., Zhou, X., Sze, S.-H., Liou, L. W., Barefoot, A., Dickman, M., and Zhang, X. 2011. Arabidopsis Argonaute10 specifically sequesters miR166/165 to regulate shoot apical meristem development. Cell 145:242-256. 